\title{
DSM-IV-TR "pain disorder associated with psychological factors" as a nonhysterical form of somatization
}

\author{
Massimiliano Aragona MD¹, Lorenzo Tarsitani MD PhD², Serena De Nitto PsyD², Maurizio Inghilleri MD PhD³
}

\begin{abstract}
M Aragona, L Tarsitani, S De Nitto, M Inghilleri. DSM-IV-TR "pain disorder associated with psychological factors" as a nonhysterical form of somatization. Pain Res Manage 2008;13(1):13-18.
\end{abstract}

BACKGROUND: Elevated Minnesota Multiphasic Personality Inventory (MMPI) scores on the hysteria $(\mathrm{Hy})$ scale are reported in several forms of pain. Previous results were possibly biased by diagnostic heterogeneity (psychogenic, somatic and mixed pain syndromes included in the same index sample) or Hy heterogeneity (failure to differentiate $\mathrm{Hy}$ scores into clinically meaningful subscales, such as admission of symptoms [Ad] and denial of symptoms [Dn]).

METHODS: To overcome this drawback, 48 patients diagnosed as having a Diagnostic and Statistical Manual of Mental Disorders, $4^{\text {th }}$ edn, Text Revision (DSM-IV-TR) diagnosis of "pain disorder associated with psychological factors" were compared with 48 patients experiencing somatic pain excluding psychological factors, and 42 somatic controls without pain.

RESULTS: MMPI Hy and hypochondriasis $(\mathrm{Hs})$ scores were significantly higher in the pain disorder group than in control groups, who scored similarly. MMPI correction (K) scores and Dn scores were similar in the three groups, whereas Ad was significantly higher in the pain disorder group and lower and similar in the two control groups, respectively. In the pain disorder group, Ad and Dn were negatively correlated, whereas in control groups they were unrelated.

CONCLUSIONS: These findings suggest that whereas a pattern of high $\mathrm{Hs}$ and Hy scores together with a normal $\mathrm{K}$ score might characterize patients with a pain disorder associated with psychological factors, elevated Hy scores per se do not indicate hysterical traits. In the pain disorder group, elevated Hy scores reflected the Ad subscale alone, indicating a strikingly high frequency of distressing somatic symptoms. They tend not to repress or deny the emotional malaise linked to symptoms, as the hysterical construct expects. The pain disorder designation should be considered a nonhysterical form of somatization.

Key Words: Chronic pain; Hysteria; Idiopathic pain; Psychogenesis; Psychogenic pain; Somatoform pain

\section{«Trouble douloureux associé à des facteurs psychologiques » selon le DSM-IV-R, considéré comme une forme non hystérique de somatisa- tion}

CONTEXTE : Des scores élevés à l'inventaire multiphasique de la personnalité du Minnesota (MMPI) sont enregistrés à l'échelle d'hystérie pour plusieurs formes de douleur. Les résultats sont peut-être faussés par l'hétérogénéité des diagnostics (syndromes douloureux psychogènes, somatiques ou mixtes, inclus dans le même échantillon index) ou l'hétérogénéité des formes d'hystérie (la non-différenciation des scores d'hystérie en souséchelles significatives sur le plan clinique comme la reconnaissance des symptômes ou la dénégation des symptômes).

MÉTHODE : Afin de surmonter la difficulté, nous avons comparé 48 patients atteints d'un «trouble douloureux associé à des facteurs psychologiques » tel qu'il est défini dans le Manuel diagnostique et statistique des troubles mentaux, 4 e édition révisée (DSM-IV-R) avec 48 patients éprouvant de la douleur somatique non associée à des facteurs psychologiques et 42 sujets témoins atteints de somatisation mais exempts de douleur.

RÉSULTATS : Les scores d'hystérie et d'hypocondrie enregistrés au MMPI étaient sensiblement plus élevés dans le groupe de patients atteints d'un trouble douloureux que dans les groupes témoins qui ont obtenu des scores comparables. Les scores de correction et de dénégation étaient à peu près du même ordre de grandeur dans les trois groupes, mais la reconnaissance était forte dans le groupe de patients atteints d'un trouble douloureux, et faible ou similaire dans les deux groupes témoins, respectivement. Dans le groupe de patients atteints d'un trouble douloureux, la reconnaissance et la dénégation étaient en corrélation négative, tandis que, dans les groupes témoins, il n'y avait pas de relation.

CONCLUSIONS : D'après les résultats, il se pourrait que la réunion de scores élevés d'hypocondrie et d'hystérie et d'un score normal de correction puisse caractériser les patients atteints d'un trouble douloureux associé à des facteurs psychologiques, mais des scores élevés d'hystérie ne constituent pas en soi des résultats indicateurs de traits de caractère hystérique. Dans le groupe de patients atteints d'un trouble douloureux, des scores élevés d'hystérie n'avaient de valeur qu'à la sous-échelle de la reconnaissance, ce qui est révélateur d'une très forte fréquence de symptômes de détresse somatique. Ils n'avaient pas tendance à refléter une répression ou une dénégation des troubles affectifs liés aux symptômes, comme ce pourrait être le cas dans le construit hystérique. Aussi l'appellation « trouble douloureux » devrait-elle être considérée comme une forme non hystérique de somatisation.

${ }^{1}$ Faculty of Philosophy, University of Rome "La Sapienza", Italy. ${ }^{2}$ Department of Psychiatric Sciences and Psychological Medicine, University of Rome "La Sapienza", Italy. "3epartment of Neurological Sciences, University of Rome "La Sapienza", Italy.

Correspondence: Dr Massimiliano Aragona, Sapienza, Università di Roma, Insegnamento di Filosofia della Psicopatologia, Stanza 203, via Carlo

Fea 2, 00161 Rome, Italy. Telephone 39-339-711-9021, fax 39-06-972-51263, e-mail massimiliano.aragona@uniroma.it 
T he Diagnostic and Statistical Manual of Mental Disorders, $4^{\text {th }}$ edn, Text Revision (DSM-IV-TR) "pain disorder associated with psychological factors" is a somatoform disorder in which pain is a somatization independent from depression, anxiety or delusion. An early classic hypothesis linked this kind of pain to hysterical features. According to Merskey (1), this was the $19^{\text {th }}$ century solution to the problem of pain without a lesion. Until recently, somatoform pain has been regarded as equivalent to pain of conversion hysteria (2). The concept of somatization is nevertheless problematic because the term is used in various ways and meanings that often bear no relation to the concept of hysteria (3).

In the original conceptualization of the Minnesota Multiphasic Personality Inventory (MMPI) hysterical ( $\mathrm{Hy}$ ) scale, two main features of the classical concept of hysteria were considered: the tendency to express emotional sufferance through somatic complaints, and the belle indifférence - a term used by classical psychopathologists to indicate an inappropriate reduction of emotional concern for symptoms. Hysterical traits assessed with the Hy scale of the MMPI were reported in chronic pain $(4,5)$, lower back pain $(6,7)$, temporomandibular pain syndromes $(8,9)$, musculoskeletal pain (10) and headache $(11,12)$. Moreover, elevated Hy scores can be a predictive factor of pain onset $(13)$, chronic course $(7,14)$ and treatment resistance (15). Finally, elevated Hy scores were among the factors predicting chronic pain in a large 30-year follow-up (16). Despite this body of evidence, the causal relation between hysterical traits and pain symptoms remains largely unclear (17), probably because of methodological shortcomings. First is the problem of diagnostic heterogeneity. For example, the frequently used diagnosis of chronic pain does not distinguish the somatic lesion or dysfunction component of pain from its psychogenic or somatoform determinants $(18,19)$. Similar heterogeneity besets other diagnostic categories (ie, lower back pain, headache, orofacial pain). Hence, with heterogeneous diagnoses, Hy scores may be elevated if the study sample included a subgroup of patients with psychogenic or somatoform pain. The second problem is Hy scale heterogeneity. Indeed, the Hy scale contains items of two distinct types - those involving somatic complaints and dissatisfaction, and those involving the denial of psychological dissatisfaction, social anxiety and distress. These items are grouped in two Hy subscales: the admission of symptoms (Ad) scale and the denial of symptoms (Dn) scale. In hysterical patients, the Ad and Dn subscales were reported to be elevated and to correlate positively with each another $(20,21)$. However, in nonhysterical patients presenting with somatic symptoms, Ad scores should be high but Dn scores should be low. Accordingly, even though patients with chronic pain have elevated Hy scores, a closer analysis of the Ad-Dn correlation showed that they exhibited the normal (negative correlation) rather than the hysterical (positive correlation) pattern (4). Although this study correctly addressed the problem of Hy heterogeneity, it focused on chronic pain patients, therefore incurring the methodological problem of diagnostic heterogeneity.

To our knowledge, only two previous papers avoided diagnostic heterogeneity by studying the role of hysteria in patients with psychogenic pain. The first reported that psychogenic pain and conversion symptoms correlated and demonstrated high overlap, suggesting that they be considered elements of a single disorder (22). Nevertheless, because correlations were tested in 29 hysterical patients, the conclusions can hardly be generalized to the entire population of patients with psychogenic pain. The second study (23) focused on 37 patients fulfilling DSM-IV criteria for the pain disorder classification. Of these patients, $72.9 \%$ scored higher than normal values on the Hy scale, but the correlation between Ad and Dn subscales was significantly negative, suggesting that high Hy scores could reflect the presence of somatic symptoms. The lack of a control group with pain of somatic origin prevented the investigators from exploring whether Hy scores were high owing to the presence of pain (independently from its etiology) or whether Hy elevation was specifically linked to the selection of a sample of patients with psychogenic pain.

In the present controlled study, we investigated the role of hysterical features in patients diagnosed as having a DSM-IVTR "pain disorder associated with psychological factors". To avoid bias arising from diagnostic heterogeneity, we selected patients with pure somatoform pain (no documented organic disease and the presence of psychological factors related to pain). We compared the results with those from two control groups whose somatic symptoms were clearly based on an organic lesion or dysfunction and were not related to psychopathological factors. To account for Hy heterogeneity, we studied the relative correlation between the Ad and Dn subscales of the Hy scale.

\section{Patient selection}

\section{METHODS}

Study participants of either sex were selected from patients aged 18 years or older attending the outpatient pain centre, and the outpatient day hospital and inpatient neurological units at the III Neurological Clinic, University of Rome "La Sapienza". To be included in the study, patients underwent a diagnostic procedure expressly designed to minimize the rate of false negatives and misdiagnosed cases (19). The same procedure was effectively used in previous research (24). All recruited patients first underwent diagnostic assessment and clinical examination by a neurologist, who assessed possible somatic lesions or dysfunctions causing the clinical symptoms using laboratory testing, radiological investigations (computed tomography scan, magnetic resonance imaging and scintigraphy), neurophysiological studies as required and referring to other specialists to clarify the final diagnosis. In cases of disagreement about the causal role of somatic findings in the development of symptoms, an independent clinical referent was asked to give a final diagnostic judgement. A psychiatrist then clinically assessed the role of psychopathological components in the development or exacerbation of pain, or both. A first diagnostic interview was followed by two or more interviews to seek information on psychopathological factors and personality features that may render the subject vulnerable to the development of somatoform symptoms, systemic relational problems and stressful life events. In doubtful cases, a final diagnostic consensus was reached through a group discussion among clinicians. The role of psychopathological factors was assessed in all subjects.

General exclusion criteria included a history of substance abuse or dependence, a diagnosis of a comorbid Axis I mental disorder (only subthreshold symptoms were accepted), and a diagnosis of dementia or significant cognitive impairment. To maximize statistical differences, mixed cases such as patients with the DSM-IV-TR classification "pain disorder associated with both psychological factors and a general medical condition", 
TABLE 1

Diagnoses of the control groups

\begin{tabular}{ll}
\hline Diagnosis & $\mathbf{n}$ \\
\hline Somatic pain & 15 \\
Intervertebral disc protrusion & 10 \\
Neuropathy & 8 \\
Cephalalgia & 7 \\
Arthropathy & 3 \\
Abdominal pain & 2 \\
Dystonia & 2 \\
Trigeminal neuralgia & 1 \\
Obliterative arteriopathy & \\
No pain & 11 \\
Multiple sclerosis & 6 \\
Myasthenia gravis & 6 \\
Stroke & 5 \\
Epilepsy & 4 \\
Painless neuropathy & 4 \\
Parkinson disease & 2 \\
Amyotrophic lateral sclerosis & 2 \\
Myositis & 1 \\
Restless leg syndrome &
\end{tabular}

and patients with nonpainful somatoform symptoms, who may have psychopathological features similar to those patients with somatoform pain, were excluded (25).

The preliminary diagnostic procedures yielded a study sample of 138 patients belonging to three groups. The index group consisted of 48 patients with a DSM-IV-TR pain disorder (PD) associated with psychological factors, no documentable organic disease but psychological factors that might have influenced the onset or clinical course of pain symptoms. The two control groups consisted of 48 patients with pain of somatic origin (SP) without related psychopathological factors, and 42 patients with nonpainful somatic symptoms due to an organic cause and no identifiable psychopathological factors that might have influenced their symptoms report (no pain, NP). Physical diagnoses of both control groups are described in Table 1.

Procedure

After completing the diagnostic procedure, eligible patients were informed of the aims and procedures of the study and gave their informed consent to participate.

In the two pain groups (PD and SP), pain was self-assessed with the total Pain Rating Index (tPRI) of the McGill Pain Questionnaire (26). To be included in the NP group, patients had to score zero on McGill's Present Pain Index and have no reported pain symptoms in the previous month. In this case, the second section of the McGill Pain Questionnaire was not administered. Each participant in the three groups had to complete the Zung Self-Rating Depression Scale (Zung-D) (27), the 20-item Toronto Alexithymia Scale (TAS-20) (28) and three scales of the first version of the MMPI (29): the K, Hs and Hy scales.

\section{Statistical analysis}

The primary dependent measures were the MMPI Hy scale and its two subscales, the Ad and Dn. Differences in the data for these measures were tested for significance with a one-way
TABLE 2

Demographic and pain characteristics of the study samples

\begin{tabular}{lcccc}
\hline & $\begin{array}{c}\text { Pain } \\
\text { disorder }\end{array}$ & $\begin{array}{c}\text { Somatic } \\
\text { pain }\end{array}$ & No pain & $\mathbf{P}$ \\
\hline $\mathrm{n}$ & 48 & 48 & 42 & \\
Female/male ratio & $33 / 15$ & $34 / 14$ & $23 / 19$ & $0.228^{*}$ \\
${\text { Age }(\text { years })^{\dagger}}$ & $51.8 \pm 15.4$ & $49.3 \pm 16.2$ & $50.1 \pm 14.3$ & $0.724^{*}$ \\
Years of education $^{\dagger}$ & $9.7 \pm 4.7$ & $10.5 \pm 4.6$ & $12.1 \pm 4.5$ & $0.175^{*}$ \\
tPRI score $^{\dagger}$ & $37.6 \pm 18.4$ & $36.4 \pm 16.2$ & - & $0.740^{*}$ \\
\hline
\end{tabular}

${ }^{*}$ Not significant; ${ }^{\dagger}$ Results presented as mean \pm SD. tPRI Total Pain Rating Index of the McGill Pain Questionnaire

TABLE 3

MMPI scales and subscales (raw scores, mean \pm SD), TAS20 and Zung-D scores of the three study samples

\begin{tabular}{lcccc}
\hline & $\begin{array}{c}\text { Pain } \\
\text { disorder }\end{array}$ & $\begin{array}{c}\text { Somatic } \\
\text { pain }\end{array}$ & \multicolumn{1}{c}{ No pain } & $\begin{array}{c}\text { ANOVA: } \\
\text { F; P }\end{array}$ \\
\hline MMPI-Hy & $30.67 \pm 5.67$ & $26.25 \pm 7.09$ & $26.4 \pm 10.34$ & $4.613 ; 0.012$ \\
MMPI-Hy Ad & $16.43 \pm 6.13$ & $13.04 \pm 4.85$ & $11.57 \pm 5.24$ & $8.702 ; 0.0001$ \\
MMPI-Hy Dn & $12.13 \pm 4.39$ & $12.06 \pm 4.97$ & $11.45 \pm 3.35$ & $0.312 ; 0.732^{*}$ \\
MMPI-Hs & $23.89 \pm 6.02$ & $20.21 \pm 5.66$ & $19.31 \pm 7.33$ & $6.710 ; 0.002$ \\
MMPI-K & $13.48 \pm 4.56$ & $13.15 \pm 4.35$ & $13.10 \pm 3.90$ & $0.096 ; 0.909^{*}$ \\
TAS-20 & $48.77 \pm 12.41$ & $48.88 \pm 10.54$ & $48.24 \pm 11.85$ & $0.037 ; 0.964^{*}$ \\
Zung-D & $42.88 \pm 10.86$ & $38.94 \pm 7.90$ & $38.31 \pm 8.27$ & $3.406 ; 0.036$ \\
\hline
\end{tabular}

${ }^{*}$ Not significant. Ad Admission of symptoms subscale; Dn Denial of symptoms subscale; Hs Hypochondriasis scale; Hy Hysteria scale; K Correction scale; MMPI Minnisota Multiphasic Personality Inventory; TAS-20 20-item Toronto Alexithymia Scale; Zung-D Zung Self-Rating Depression Scale

ANOVA followed by post hoc analysis using Scheffé multiple comparisons. Pearson product moment correlation was used to test correlations of Ad and Dn scores between groups. A oneway ANOVA was used to determine possible significant differences among groups in the MMPI Hs and K scales, the TAS-20 and the Zung-D. Differences in demographic and clinical variables among groups were assessed with $\chi^{2}$ test for categorical variables and the ANOVA or Student's $t$ test, when appropriate, for continuous variables. A two-tailed $\alpha$ level of 0.05 was considered significant. All data were analysed using SPSS base 12 (SPSS Inc, USA).

\section{RESULTS}

No significant differences were found between age, sex and years of education among the three groups (Table 2). The tPRI scores did not differ significantly between the PD and SP groups.

The mean Hy score differed significantly among the three groups (Table 3). Further analyses using the Scheffé test disclosed significant differences between patients with PD and control patients with SP $(\mathrm{P}=0.024)$. The difference between PD and NP approached statistical significance (post hoc test: $\mathrm{P}=0.055)$. The two control groups did not differ in Hy scores (post hoc test: $\mathrm{P}=0.972$, not significant). Analysis of the Hy Ad and Dn subscales showed that Ad scores were significantly higher in the group of patients with PD than in those with SP (post hoc test: $\mathrm{P}=0.016$ ) and with NP (post hoc test: $\mathrm{P}=0.0001)$, whereas no significant differences were found in 
Dn scores among the three groups (Table 3). Pearson correlation analysis disclosed no significant correlation between $\mathrm{Ad}$ and Dn scores either in the whole sample $(r=-0.129, P=0.142$, two-tailed) or in the two control groups (SP, $r=0.040, \mathrm{P}=0.789$; $\mathrm{NP}, \mathrm{r}=0.001, \mathrm{P}=0.994$, two-tailed). A significant negative correlation was found between $\mathrm{Ad}$ and $\mathrm{Dn}$ scores in the PD group ( $r=-0.489, \mathrm{P}=0.001$, two-tailed).

The mean Hs score was significantly higher in the PD group than in both control groups (post hoc test: $\mathrm{P}=0.007$ versus SP group; $\mathrm{P}=0.001$ versus NP group) but did not differ significantly between control groups (post hoc test: $\mathrm{P}=0.732$ ). There were no significant differences among groups in MMPI $\mathrm{K}$ scale scores or in TAS-20 scores (Table 3). Although Zung-D scores differed significantly among groups (Table 3), Scheffé post hoc comparison showed that the difference approached significance only between the PD group and NP controls $(\mathrm{P}=0.065)$.

\section{DISCUSSION}

Our findings in the present controlled study show that hysterical features play no role in patients presenting with a DSMIV-TR pain disorder associated with psychological factors (PD). Even though higher Hy scores in patients with PD than in the two control groups could be superficially interpreted as a sign of hysteria, the significant negative correlation found between Ad and Dn scores in the PD group differed from what would normally be expected in hysterical patients. Hence, somatoform or psychogenic pain may be better conceived as a form of somatization independent from hysterical mechanisms. This finding confirms previous uncontrolled studies (23) and corroborates Merskey's suggestion (1) to regard somatoform pain as a form of somatization different from hysterical conversion.

In particular, the analysis of the Ad and Dn subscales showed that the Hy elevation in patients with PD arose exclusively from the contribution of the Ad subscale. This suggested that patients with PD tend to complain of somatic symptoms more than patients in the other two clinical groups, independent of a hysterical denial of symptoms. In patients with PD, this evidence was also supported by the complementary elevation of Hs scores - reflecting the overlap between Ad and Hs together with normal K scores. Accordingly, many Hs items measure somatic complaints (similar to the Ad subscale) while the $\mathrm{K}$ and Dn scales share nine items and report a high correlation in pain samples (4).

Another finding is that Hy and Hs scores were significantly higher in patients with PD than in SP controls. This suggested that when mixed cases (for example, those included in heterogeneous diagnoses such as chronic pain, or in mixed categories such as DSM-IV-TR "pain disorder associated with both psychological factors and a general medical condition") are ruled out, elevated Hy and Hs scores may be useful in distinguishing pure somatoform pain from pain due to an organic lesion or dysfunction. Accordingly - though our small study sample precluded us from offering a definitive answer to the problem this finding added new evidence to the classic debate on the failure of the MMPI to distinguish between organic and psychogenic pain (30). Our study therefore suggests that the MMPI scales can distinguish organic from psychogenic pain far better when diagnostic heterogeneity is preliminarily excluded.

We consider it unlikely that these findings were biased by other major variables: demographic and pain characteristics (Table 2) and TAS-20 scores were similar in the three groups.
The similar TAS-20 scores in the present study contrast with previous research (31), which found elevated alexithymia scores in chronic pain, and deserve further investigation. One possible explanation for this finding is that the stringent exclusion criteria of the study eliminated much of the psychopathology (ie, depressive and anxiety comorbidity) that usually results in elevated TAS-20 scores. Beyond this possible general explanation, the fact that the alexithymia scores did not differ between groups partially supports the rejection of the hysterical hypothesis, because alexithymic features are part of the classic description of hysterical mechanisms (ie, the inability to express emotional difficulties, converted into somatic symptoms). At the same time, it should be stressed that alexithymia is a much larger concept that encompasses a large range of disorders and personality structures (ie, obsessivity). Accordingly, alexithymic findings alone cannot be used to test the hysterical hypothesis, but taken together with $\mathrm{Hy}$ and $\mathrm{Hs}$ scores they may complement the above-discussed results.

Whether depressive symptoms influenced our results is unclear. Zung-D scores differed significantly among the three groups $(\mathrm{P}=0.036)$, although the post hoc analysis showed no significant differences. Because our study procedures for selecting patients explicitly excluded mood disorders, slight statistical differences in Zung-D scores presumably depend on the presence of subthreshold depressive phenomena. Further studies including depressive comorbidity may clarify the relationship between mood and PD.

Our study has three other possible limitations. First, although we carefully designed the diagnostic procedure to reduce diagnostic heterogeneity, some diagnostic problems were unavoidable. We may have failed to exclude a possible somatic cause of symptoms, because this depends on current knowledge and the diagnostic ability of the involved clinicians. For example, although in cases of diffuse myalgia we carefully tried to exclude possible rheumatic etiology, some degree of misclassification remains possible. Some symptoms diagnosed as idiopathic could therefore eventually prove to be somatically caused, representing a source of possible bias. Moreover, the second-step clinical judgment of a relationship between psychopathological features and somatic symptoms remains a matter of subjective interpretation. Accordingly, to have diagnosed our index sample as PD according to DSM-IVTR may be criticized by somatically oriented physicians, who may have preferred to diagnose these cases as forms of idiopathic pain of unexplained somatic origin (ie, musculoskeletal dysfunctions not yet clarified). We have to recognize that this last alternative interpretation of the clinical picture is not less valid than our diagnostic method, and that our decision to use DSM-IV-TR criteria is based on the belief that the diagnosis of PD, although questionable, still has some utility (32).

The second limitation is that, having selected pure cases, our patients cannot be expected to correspond exactly to pain patients who usually attend clinical settings. In fact, pain is a biopsychosocial and multifaceted phenomenon. In clinical settings, pain diagnoses are distributed along a continuum in which psychological and somatic factors are strictly intertwined. In contrast with this usual presentation in clinical settings, the two pain diagnoses in our study were relatively pure (patients were positioned at the extremes of the clinical spectrum of pain presentation) and therefore quite rare. Accordingly, the limit was that of poor clinical generalization of our findings. Nevertheless, it should be stressed that this 
limit was counterbalanced by high specificity, because enucleating pure samples is the best way to let differences emerge clearly.

The third possible source of bias is that we administered only three MMPI subscales, taken out of context, and presented the questions in an unusual order. The busy clinical routine in the outpatient service would have made it difficult to administer the whole MMPI to all the included patients. To avoid a bias from selecting the most compliant patients, we decided to use a shorter psychometric battery. The scales were limited to those that McGrath and O'Malley (33) suggested to consider simultaneously when evaluating the roles of $\mathrm{Ad}$ and $\mathrm{Dn}$ of symptoms. The unusual presentation of the MMPI scales remains a limit that needed to be underlined, because the results may have limited relevance for clinicians using the whole version of the MMPI.

\section{CONCLUSIONS}

The present findings suggested that a pattern of high Hy and Hs scores together with a normal $\mathrm{K}$ may characterize patients with a DSM-IV-TR pain disorder associated with psychological factors, although elevated Hy total scores per se cannot be considered an expression of hysterical traits. The relative interplay between the two Hy subscales (Ad and Dn) must be taken into account to study hysterical features. Our PD patients showed a significant negative correlation between Ad and Dn, and had significantly higher Ad scores than control groups. This pattern indicated that PD patients presented with a strikingly high frequency of distressing somatic symptoms, and

\section{REFERENCES}

1. Merskey H. Pain disorder, hysteria or somatization? Pain Res Manag 2004;9:67-71.

2. Mai FM. "Hysteria" in clinical neurology. Can J Neurol Sci 1995;22:101-10.

3. Merskey H. Pain, psychogenesis, and psychiatric diagnosis. Int Rev Psychiatry 2000;12:99-102.

4. Watson D. Neurotic tendencies among chronic pain patients: An MMPI item analysis. Pain 1982;14:365-85.

5. Magnani B, Johnson LR, Ferrante FM. Modifiers of patientcontrolled analgesia efficacy. II. Chronic pain. Pain 1989;39:23-9.

6. Fordyce WE, Bigos SJ, Batti'e MC, Fisher LD. MMPI scale 3 as a predictor of back injury report: What does it tell us? Clin J Pain 1992;8:222-6.

7. Akerlind I, Hörnquist JO, Bjurulf P. Psychological factors in the long-term prognosis of chronic low back pain patients. J Clin Psychol 1992;48:596-605.

8. Michelotti A, Martina R, Russo M, Romeo R. Personality characteristics of temporomandibular disorder patients using MMPI. Cranio 1998;16:119-25.

9. Meldolesi G, Picardi A, Accivile E, Toraldo di Francia R, Biondi M. Personality and psychopathology in patients with temporomandibular joint pain-dysfunction syndrome. A controlled investigation. Psychother Psychosom 2000;69:322-8.

10. Kvåle A, Ellertsen B, Skouen JS. Relationships between physical findings (GPE-78) and psychological profiles (MMPI-2) in patients with long-lasting musculoskeletal pain. Nord J Psychiatry 2001;55:177-84.

11. Andrasik F, Blanchard EB, Arena JG, Teders SJ, Teevan RC, Rodichok LD. Psychological functioning in headache sufferers. Psychosom Med 1982;44:171-82.

12. Mongini F, Ferla E, Maccagnani C. MMPI profiles in patients with headache or craniofacial pain: A comparative study. Cephalalgia 1992;12:91-8.

13. Pietri-Taleb F, Riihimäki H, Viikari-Juntura E, Lindström K, Moneta GB. The role of psychological distress and personality in the incidence of sciatic pain among working men. Am J Public Health 1995;85:541-5. tended not to repress or deny the emotional malaise linked to symptoms (as expected in the hysterical belle indifférence). Accordingly, in our PD patients, pain could not be considered the somatic expression of repressed psychological conflicts through classic hysterical mechanisms.

These data are consistent with previous reports that suggested classifying this kind of pain as a form of somatization different from hysterical conversion (1). This supports a reconceptualization of the possible psychogenesis of these forms of pain. An early similar conceptual evolution (34) started by considering psychogenic regional pain as a form of hysterical pain, but later admitted that it was "evoked not only in hysterical states and conversion reactions but in all the neuroses and psychoses at times when the patient feels threatened, hurt, harmed, or injured" (35). Accordingly, other possible factors differing from hysteria that could be implicated in pain disorders should be considered. Among others, potential psychogenic factors involved are hypochondriac tendencies (fear or belief of having a disease, consequent repetitive body checking and possible cognitive facilitation of the perception of body symptoms), catastrophizing, pain-fear, and increased susceptibility to pain. Furthermore, attachment styles and the role of pain behaviour in eliciting interpersonal reinforcements may be involved (36). Further studies on these factors are needed to clarify the mechanisms underlying somatoform pain.

ACKNOWLEDGEMENTS: The authors thank Lara Bancheri, MD, Antonella Conte, MD, and Alessia Pizzimenti, PsyD, for their fundamental help.
14. Gatchel RJ, Polatin PB, Kinney RK. Predicting outcome of chronic back pain using clinical predictors of psychopathology: A prospective analysis. Health Psychol 1995;14:415-20.

15. Taylor WP, Stern WR, Kubiszyn TW. Predicting patients' perceptions of response to treatment for low-back pain. Spine 1984;9:313-6.

16. Applegate KL, Keefe FJ, Siegler IC, et al. Does personality at college entry predict number of reported pain conditions at mid-life? A longitudinal study. J Pain 2005;6:92-7.

17. Vendrig AA. Minnesota multiphasic personality inventory (MMPI). Spine 1996;21:1939-40.

18. Waid SJ, Paitenay RK, Yaksh TL. Nociceptive models: Relevance to clinical pain states. In: Basbaum AI, Besson JM, eds. Toward a New Pharmacotherapy of Pain. New York: Wiley, 1991:381-92.

19. Perinelli D, Bancheri L, Pizzimenti A, Conte A, Inghilleri M, Aragona M. Clinical evaluation of the diagnostic problems in the DSM-IV-TR “pain disorder” classification. Med Psicosom 2001;46:133-40.

20. Little KB, Fisher J. Two new experimental scales of the MMPI. J Consult Psychol 1958;22:305-6.

21. Marks, PA, Seeman W. The Actuarial Description of Abnormal Personality: An atlas for use with the MMPI. Baltimore: Williams \& Wilkins, 1963

22. Watson CG, Tilleskjor C. Interrelationships of conversion, psychogenic pain, and dissociative disorder symptoms. J Consult Clin Psychol 1983;51:788-9.

23. Conte A, Perinelli D, Bancheri L, Pizzimenti A, Aragona M, Inghilleri M. Psychological mechanism involved in pain syndromes not fully explained on a somatic base: The role of hysteria. Med Psicosom 2000;45:123-30.

24. Aragona M, Bancheri L, Perinelli D, et al. Randomized doubleblind comparison of serotonergic (Citalopram) versus noradrenergic (Reboxetine) reuptake inhibitors in outpatients with somatoform, DSM-IV-TR pain disorder. Eur J Pain 2005;9:33-8.

25. Hiller W, Heuser J, Fichter MM. The DSM-IV nosology of chronic pain: A comparison of pain disorder and multiple somatization syndrome. Eur J Pain 2000;4:45-55. 
26. Melzack R. The McGill Pain Questionnaire: Major properties and scoring methods. Pain 1975;1:277-99.

27. Zung WW. A self-rating depression scale. Arch Gen Psychiatry 1965;12:63-70.

28. Bagby RM, Parker JD, Taylor GJ. The twenty-item Toronto alexithymia scale - I. Item selection and cross-validation of the factor structure. J Psychosom Res 1994;38:23-32.

29. Hathaway SR, McKinley JC. Manual for the administration and scoring of the MMPI. Minneapolis: National Computer Systems, 1983.

30. Vendrig AA. The Minnesota Multiphasic Personality Inventory and chronic pain: A conceptual analysis of a long-standing but complicated relationship. Clin Psychol Rev 2000;20:533-59.
31. Lumley MA, Asselin LA, Norman S. Alexithymia in chronic pain patients. Compr Psychiatry 1997;38:160-5.

32. MacDonald MR. Pain disorder diagnosis: Still some utility. Pain Res Manag 2004;9:213.

33. McGrath RE, O'Malley WB. The assessment of denial and physical complaints: The validity of the Hy scale and associated MMPI signs. J Clin Psychol 1986;42:754-60.

34. Walters A. Psychogenic regional pain alias hysterical pain. Brain 1961;84:1-18.

35. Walters A. The significance of the psychogenic regional pain syndrome. Psychosom Med 1966;28:771-772. (Abst)

36. Stuart S, Noyes R Jr. Attachment and interpersonal communication in somatization. Psychosomatics 1999;40:34-43. 


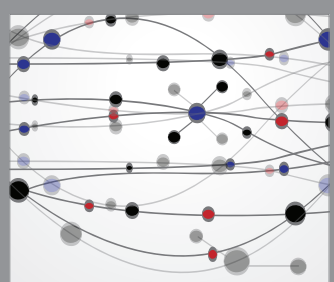

The Scientific World Journal
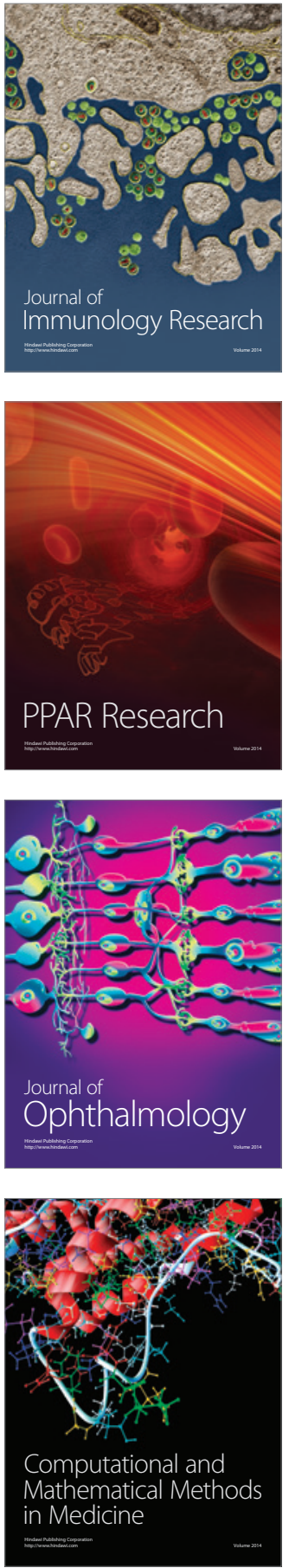

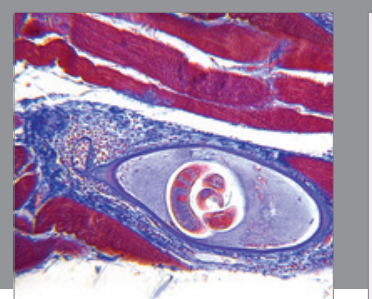

Gastroenterology Research and Practice

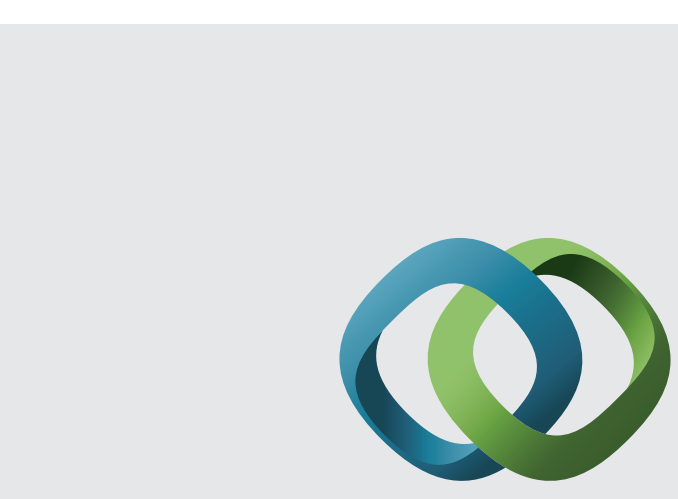

\section{Hindawi}

Submit your manuscripts at

http://www.hindawi.com
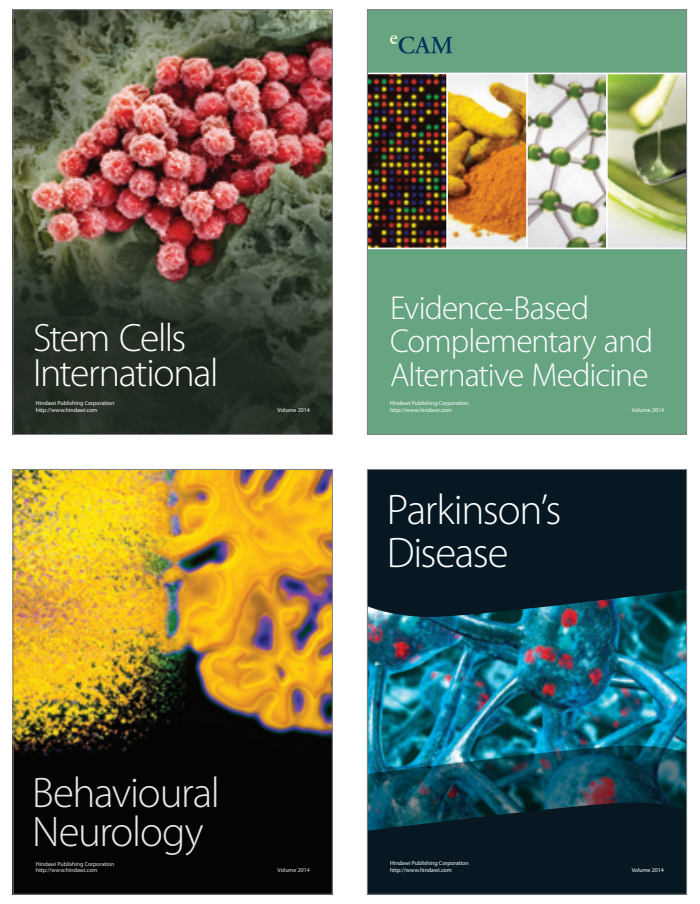
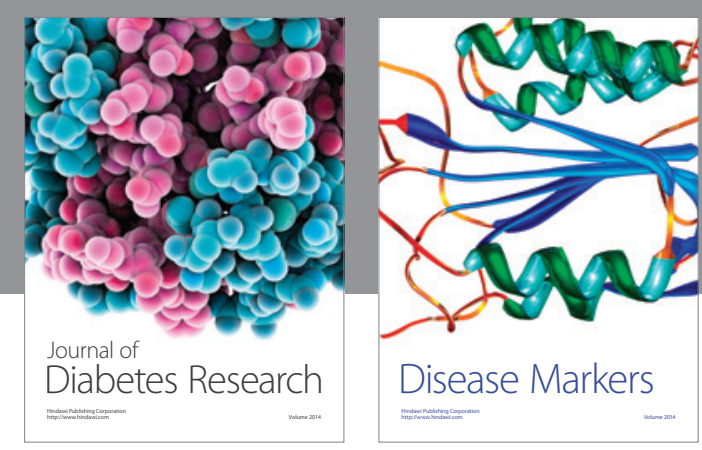

Disease Markers
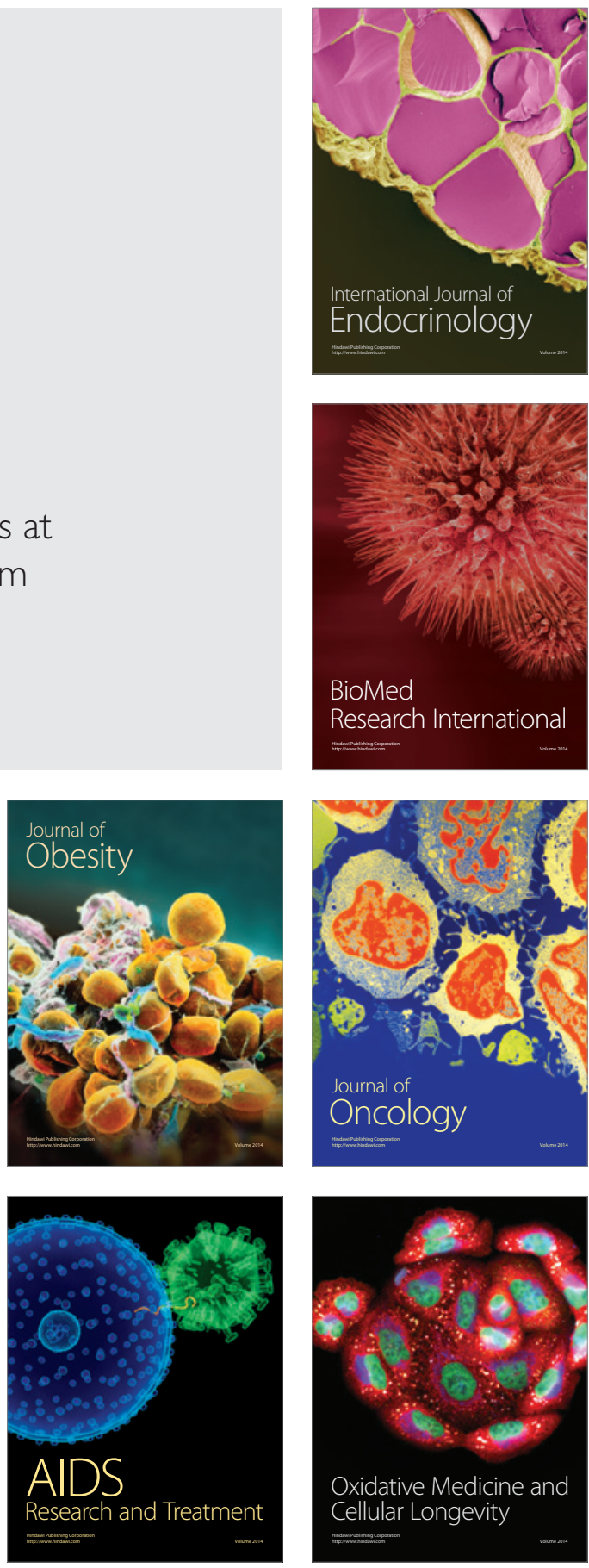